\title{
DIGITAL LEARNING TECHNOLOGIES IN PROCESSES OF INNOVATION AND DEMOCRATIC CHANGE? - REFLECTIONS AND QUESTIONS
}

\author{
Elsebeth Wejse Korsgaard Sorensen, Aalborg University, Denmark
}

"Nothing influences our abilities to cope with the difficulties of existence, so much as the context in which we view them" (Zeldin, 1994)

\section{Introduction}

Innovation with digital technologies in formal teaching and learning processes with the purpose of educating learners to become global citizens suffers from inertia. In particular, when it comes to innovation with digital technologies within processes of collaboration and dialogue. It seems that digital dialogue in education utilized for democratic change appears a complex challenge to address. However, historically, new technological innovations have often been rejected. It takes a long time to become accustomed to new technology and to realise its advantages, let alone to be actively utilized (Castells, 1998). Regardless of attitudes towards technology in general, the arguments have been strong for preparing learners for a future in a society permeated with digital technologies.

On the collaborative and dialogic fronts, however, the challenges seemed more complex. While digital technologies seem to have led to enhanced collaboration between teachers (in terms of use and re-use of resources), the promotion of student collaboration has not been enhanced notably. This corresponds to the observation pointed out by the teachers that the integration of digital technologies has not led to a real change in practice and innovation in teaching and learning methodology or alterations of teacher authority, teacher-student roles and power relationships within the learning processes.

Why does it take so long for educational communities to assert the digital perils and potential and implement the digital communicative and pedagogic potential of education of technologies in ways that cultivate, support and enhance the quality of education in general and lifelong learning (LL) in particular?

Well, on the one hand, innovative development is hampered by tradition. On the other hand, innovation does not primarily generate from research directed towards technologies and their virtues, but more often it appears as a result of the bottom-up processes of educators in their own practices - in other words, from the use context. 
In the present context, while reflecting on the contradiction, several issues and questions come to mind:

- The first issue (Q1) concerns the weight, impact and assumptions of traditions and the resulting general inertia with respect to implementing digital educational technology in innovative ways (e.g. for the cultivation of learning communities of practice) in the educational system.

- The second issue (Q2) concerns the ethical issue of "building" (general education) in a global educational perspective including: (a) the fostering of democratic citizens ("building" or socialization), (b) the promotion of ethical values, (c) the empowerment of the learners - with a focus on meta-learning.

- The third issue (Q3) concerns the pedagogical design of online learning architectures for the promotion of shared dialogue and knowledge construction.

- The forth issue (Q4) concerns teacher roles, innovation and learner-centeredness

- The fifth (Q5) issue concerns the role of technology in processes of innovation and change.

This paper reflects on these issues, and discusses the various aspects involved. The structure of the paper and the discussions evolves around identified themes, and reflections on the issues and on their contextual premises are provided. The themes are: (a) The weight of traditions, (b) Educating ethically responsible and democratically empowered learners/citizens?, (c) The impact of pedagogic design decisions and meta-learning?, (d) Technology as vehicle in processes of innovation and change, and (e) Technology as vehicle in processes for innovation and change?

\section{The weight of traditions?}

In a research perspective we may talk about at least 3 types of research traditions, that - to a smaller or larger extent - impact on the inertia of digital innovation within teacher education (in terms of digital collaboration and dialogue.

\section{The tradition of Distance Education (DE)}

As early as in 1989, Søren Nipper coined and described the concepts of " 3 generations of DE" (Nipper, 1989):

1. Correspondence education (more than a hundred years of tradition).

2. Enhanced material concept/distribution (a focus on developing materials).

3. A "virtual" organization, using virtual learning environments (VLEs), allowing collaboration/interaction between students and between students and teachers, requiring competencies on behalf of teachers in pedagogical "organization"/ "design" of an entire virtual world/context for collaborative learning and dialogue (a qualitative shift in the evolvement of DE generations). 
Therefore, within the context of DE (especially in Norway), technology/VLE's, carrying the load of tradition, were initially implemented as add-on phenomena. Unfortunately, in a way that did not really utilize the collaborative and dialogic potential of VLEs.

\title{
The tradition of Computer Supported Collaborative Learning (CSCL)
}

Historically, within the tradition of CSCL, the collaborative potential of "virtuality" and the challenge of utilizing this in collaborative learning processes enjoyed a higher degree of awareness in the tradition. Nevertheless, as noted by Kreijns and Kirchner, as early as in 2001:

\begin{abstract}
"Support of social interaction has received little attention in the design of CSCL environment, due to the generally accepted assumption that social interaction (also in virtuality) can be taken for granted ... it is not surprising that numerous field observations report disappointing results..." (Kreijns \& Kirchner, 2001)
\end{abstract}

Admittedly, within the last decade, the CSCL community has with high priority addressed the social interaction issue CSCL (Woodruff, 2002; Stahl, 2006; Roschelle \& Teasley, 1995). Not only analytically in terms of the nature of collaborative knowledge building in itself, but also the challenge of designing virtual learning architectures that are holistically integrated for the promotion of online COP's.

Throughout the years, CSCL has also been widely known for struggling with some more "traditional" problems (Stahl, 2006):

- Group formation: How do we form groups in pedagogically sound ways?

- Social awareness: How can the learning environment provide awareness of peer learners - even if they participate remotely in the learning process? Alternatively: How can pedagogical designs provide awareness?

- Moderation/guidance/scaffolding/teacher role: How can collaborative learning processes in virtual COP's be effectively moderated/guided by a tutor/by the learning environment?

- Different interpretations of the role of dialogue in collaborative learning (Koschmann, Dillenbourg....) and what it means to collaborate virtually - and share knowledge?

- The vision of today's CSCL challenges, as identified by Gerry Stahl (2006): Opening new worlds of collaboration, where Groupware systems may create meta-structure to (a) help to create and structure communities, (b) define and generate educational realms of knowledge, give form to intentions and meaning, (c) helping users to come to an understanding of the system's designed affordances, (d) imposes new tasks and transform existing social practices, and (e) make life more rewarding, if also more complex. 


\section{The tradition of teacher education (TE)}

TE practice suffers from more conflictive issues:

- The separation between theory and practice of the education?

- The pendling shift in focus from "teaching" to "learning" from legislation?

- The minds of teacher trainees? The minds of teacher trainers? The ultimate goal of teaching is learning.....?

Is it a question of understanding the challenge of "integrated pedagogical design" for the establishment of collaboration or for the formation of communities of practice (COPs) (Wenger, 1998) in a technology-enhanced setting, or is it may be a question of understanding the didactical challenge of designing FOR collaboration in a technology-enhanced setting? To what extent - and in what sense - do these three heavy traditions and practices (DE, CSCL and TE) possibly enhance or hamper understanding and didactical innovation in relation to the challenge of forming "integrated pedagogical designs" that are conducive to the creation of innovative collaborative digital COPs (e-COPs)? Do the 3 heavy traditions (DE, CSCL and $\mathrm{TE}$ ) enhance or hamper understanding and digital innovation in relation to the challenge of forming "integrated pedagogical designs" that are conducive to innovation of formation of collaborative e-COPs?

\section{Educating ethically responsible and democratically empowered learners/citizens?}

This issue concerns ethical values. It includes utilizing the digital potential in ways that support the "production" of democratically-oriented empowered learners in a global educational perspective, including: (a) fostering democratic citizens ("building"/upbringing), (b) promoting ethical values, (c) empowering learners - with a focus on meta-learning. It denotes teachers' pedagogical promotion of ethical values and choice of non-authoritarian methodologies (learning for all, global prosperity, empowering the learner etc.). It includes teaching learners a democratic attitude through a pedagogical method that practices digital collaboration, dialogue and negotiation, with a value of co-existence and a global perspective on prosperity.

This may be done through a pedagogical focus on applying online negotiation and metalearning methodology as pedagogical method. In relation to the need for an educational Ethos of democratic dialogue and collaboration, other current international trends in learning - e.g. like lifelong learning (LL) and learning-to-learn (L2L) - could potentially be of inspiration.

A look back at the field of CSCL, the literature (ex. Crawley, 2014) states that "CSCL .... fulfills some sound educational principles, not least of which being the promotion of an educational Ethos of cooperation" (Crawley, 2014).

How to "educate" globally and multi-culturally oriented learners in becoming democratic citizens is a strong concern. As educational designers facing the challenges of our global 
society it is essential, to adapt an explicit democratic standpoint when we design. But it may not be sufficient to barely incorporate and keep transparent the ethical values of "building"/education when designing for online COP's. We also need to design and practice online pedagogical methods that "train" pedagogical values (i.e. features of becoming a global democratic citizens), and on how important it is to focus in research on pedagogical design on online learning architectures that promote collaboration and dialogue among learners.

Dialogue is the essential medium for this, but nothing - not even dialogue (in my experience) - appears out of the blue. Rather, it must be designed/induced through online designs that are conducive to dialogue and stimulate authenticity and motivation in learners). Thus, the goal and rationale behind evaluation criteria used to evaluate the dialogic process, which evolves, are based on the following rationale, when it comes to characteristics of a democratic world citizen:

The expectation to learners of what characterizes a democratic dialogue (Sorensen, 2005; Sorensen \& Brooks, 2018), could be disseminated to - and practiced with - students:

- knows how to be tolerant and supportive of a fellow human being;

- is open to new ideas and alternative solutions;

- is able to listen to others and incorporate the opinion of others in their views;

- wants to learn from each other's and share knowledge for the course of shared goals;

- does not strive or take initiatives to control others;

- does not submit to authoritarian methodology in any area, but respects the quality of the argument.

An example of a tested model of evaluation criteria for dialogue, which fits and train the democratic dialogue (Sorensen, 2005):

Quantitative evaluation:

- at least 5 contributions;

- 3 of them should be responses to contributions of other students.

Qualitative evaluation (examples of contents which enhances knowledge building):

- questions that ask for clarity;

- adding new knowledge to the discussion;

- etc.

Rationale behind criteria:

- The goal is to support digital human interaction, which contributes to the development of a democratic collaborative knowledge building negotiation and discussion:

- Participation in discussion (that learners are driving towards a shared goal);

- Response on others' contributions (the one are listening to what is said); 
- Elicit response from others (that you are contributing with relevant interesting views).

Now, one could raise the question if it is possible to implement democratic dialogic metalearning methodology (with changed teacher-learner roles), not only in in teacher training programs "locally", but also in diverse global intercultural contexts for the purpose of enhancing co-existence, promotion of dialogue and shared intercultural knowledge construction, and the building of global ecological online learning communities? Which types of problems may arise? May an overall methodology of meta-learning/double loop learning strategies, coupled by digital techniques, work for ethical change, transcendence and innovation?

\section{The impact of pedagogic design decisions and meta-learning?}

In other words, from the above discussion we may arrive at a need for issues, knowledge and advices of pedagogical design of online learning architectures for the promotion of shared dialogue and knowledge. The important thing here is the predicted interaction (the planned) and what actually emerges. In other words, the ability of teaching and learning to interact in ways, in which they become structuring resources for each other. Thus, Sorensen and Ó Murchú (2004) argue that important considerations are:

- How to minimize teaching (the predicted) in order to maximize learning?

- How to maximize processes of negotiation of meaning enabled by interaction?

Therefore, from a Wengerian perspective (Wenger, 1998), design is about creating a proper balance of participatory and reificatory elements in the instructional design:

- Which elements to structure and make procedures for on the basis of prediction?

- To what extent the design should depend on de-contextualized knowledge?

- How to balance student initiative/ownership and pedagogical authority?

Meta-learning (ML) is the most significant and powerful aspect of the learning-to-learn (L2L) phenomenon. It implies learning of meta-knowledge about learned knowledge (i.e. learning about how one learns) and learning about one's own learning, thinking and acting. L2L is part of that learning, and knowing how to learn is an important knowledge (Knowles, 1975; Garrison, 1997).

It is also important to understand how people learn in social contexts. Wenger explains the negotiation of meaning as involving two constituent processes: participation and reification. These two processes exist in duality, affecting each other and being the source of development to each other. But since production of meaning is distributed inseparably across reification and participation in a shared practice, a dynamic relationship between the two must be established in our design and facilitation of learning. If not, the negotiation and construction of meaning may become problematic: 
"If participation prevails - if most of what matters is left un-reified then there may not be enough material to anchor the specificities of coordination and to uncover diverging assumptions.(...) If reification prevails - if everything is reified, but with little opportunity for shared experience and interactive negotiation - then there may not be enough overlap in participation to recover a coordinated, relevant, or generative meaning" (Wenger, 1998; p.65)

It is a widely accepted view within pedagogical enhancement of technology, that nothing happens without a fixed shared structure - determining what, why, how, where, when. Even processes of improvisation and creativity are often happening as challenged deviations from organizations, structures, etc.

“...teachers and instructional materials becomes resources for learning in much more complex ways than through their pedagogical intentions. Teaching must be opportunistic, because it cannot control its own effects." (Wenger, 1998; p.267)

Which problems, which possibilities and what degree of importance as a catalyst for change should we anticipate would be resting on the shoulders of the teacher/designer?

\section{Technology as vehicle in processes for innovation and change?}

In different aspects or areas of society, we find different positive and negative views on the question of technology. While technology optimism is widespread, more pessimistic voices on the role of technology have also been heard over time.

One of these voices were the voice of Martin Heidegger (Heidegger, 1996). While the optimistic view perceived technology as entailing the powers of seduction/persuasion/fascination, Martin Heidegger's view was a very pessimistic one (Heidegger, 1977).

- Our fundamental relation to the world is through "the use". With modern technology man is made alien to "the use" and, therefore, to the world.

- Through our use-relationship to the world, we must accept the products of technology, although they do not commit us epistemologically.

- Technology dangerous: humans are exposed to the danger from the structure, which lies behind technology as an instrumental-economical complex.

But (Heidegger's optimism), if we seek/find the nature of technology through (a) poiesis (creation on terms which transcend the creation itself), and (b) techne (an art serving religion and philosophy), things may be different.

Now, in contrast, if we follow Heidegger's advice and focus on "use" (which may be viewed as quit in line with an emphasis on bottom-up processes and practice) and take a look at what 
happens today, mostly in informal learning communities, then we face quit a different and, from a formal educational perspective, intriguing technology scenery and practice.

It is however indisputable that Web 2.0 either works empowering on the individual and/or provides an outlet for what could be called the voice of the voiceless. In other words, social software makes possible (e.g. Anderson, 2016):

- democratization of knowledge and content (from centrally defined to user-driven content);

- moving focus from communities to networked structures;

- moving focus from consumers to producers, distributing news (participant agency).

Social software also supports the creation and maintenance of different types of networks:

- networks between people working collaboratively;

- empowering networks between people sharing a context (students and teachers within a course, use each other as resources);

- networks between people sharing a field of interest.

Consequently, this leaves us with the following pedagogical/didactical tasks:

- facilitating networks between students within the same course;

- facilitating networks between students and other people working with the field.

It is claimed that the social fabric of Web 2.0 technologies is tightly closed to the local, the place, the location and the creation of a personal, but relational identity. In a perspective of globalization, we do become more global, but not less local or grounded (Wellman, 2012):

- How might the social software transform learning culture and individual behaviours?

- What are the pedagogical changes? What are the new organizational and learning strategies with the new learning tools?

- What impact has social software had on institutionalized learning and training?

- How can best practices be identified regarding what works in e-learning, in which environments, and what does not?

- What will be the impact of open educational content and resources?

\section{Conclusion}

What may then be, in essence, the latent potential of social software, if any - for acting as catalysts for innovating TE? How does one evaluate the potential of social software and its sustainability? And what is the need for organizational and pedagogical "legitimization" (perhaps a premise for IT to play a genuine role in TE)?

"We do at times engage in conscious reflection and systematic thought, but these are secondary to the pre-reflective experience of being thrown in a situation in which we are always already acting. We are always engaged in acting within a situation, without the opportunity to fully disengage ourselves 
and function as detached observers. Even what we call "disengagement" occurs within thrownness: we do not escape our thrownness, but shift our domain of concern. Our acts always happen within thrownness and cannot be understood as the results of a process (conscious or non-conscious) of representing, planning, and reasoning." (Winograd \& Flores, 1986; p.70)

With this final statement in relation to the complexity of research perspectives, I would like to again point to Heidegger, who in my opinion - through his notion of "thrownness" - has something rather important to say about our inescapable embodiment in context.

We should remind ourselves Virtual Learning Environments provide possibilities for a different type of human interaction than that of the physical world. The virtual interaction is susceptible to a dynamic principle related to time and space (i.e. context), and has general characteristics that resemble the features of both spoken and written interaction. Although the interaction may appear as if it was spoken and share a high degree of features of spoken dialogue (due to an often high interactivity), the interaction also contains certain permanent properties, typical of traditional written interaction, which are not subject to the same dynamic time/space principle (Mason, 1993).

This paper has presented some reflections on the various aspects of the development and design of digital architectures in an international perspective. The SLAF model below is an example of such an architecture (Sorensen, 2018):

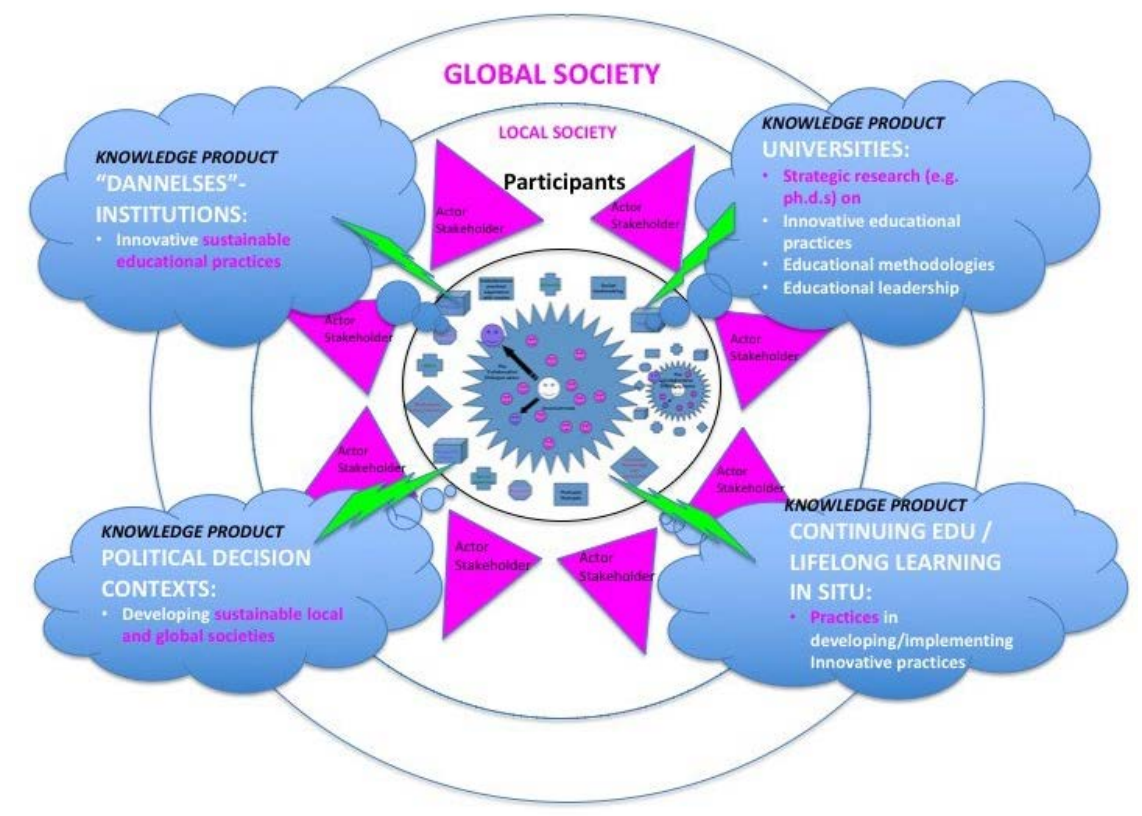

Figure 1. The SLAF model. Innovative learning and collaborative knowledge building across positions and disciplines. Innovation and data generation in situ.

SLAF serves as an inclusive and sustainable model for establishing global intercultural educational program, drawing on existing knowledge in different layers of society. 
The paper has argued for a necessity of constructing educational design models based on ethical values in terms of participation and inclusion. It makes a plea for the use of design models that enculture a fundamental dialogic/participatory approach across types of participants. It promotes non-authoritarian principles and liberating and empowering ethical values at the same time. In addition, the models have to be based in a realistic and strategic context experiencing the needs of the networked society and the knowledge economy. Key issues have been identified, described and discussed that are envisioned to promote sound sustainability and global educational growth.

SLAF (Figure 1) integrates a net-based dialogical model for collaborative knowledge building. It becomes a communicative melting pot, in which all stakeholders - across hierarchical positions and disciplines - in a "modus 2" setting participate, create and innovate in a collaborative knowledge building process in a digital learning architecture. All participants (i.e. members of society, researchers etc.) are contributors (provide input) as well as learners (gaining output). Everyone involved may be characterized as "prosumers" (Helms \& Agerbaek, 2010). All stakeholders from the four main areas of society contribute as input their insights and expertise to the collaborative work and negotiated identification/learning process, and likewise every stakeholder takes away, as output from the collaborative learning and negotiation process, exactly that which makes sense to him/her and is useful from his/her individual position and perspective. In the wording of Edwards (2007):
"(...) boundaries as spaces where the resources from different practices are brought together to expand interpretations of multifaceted tasks, and not as barriers between the knowledge and motives that characterize specialist practices. Importantly, the learning that occurs in these spaces is not a matter of learning how to do the work of others, but involves gaining sufficient insight into purposes and practices of others to enable collaboration" (2007; p.27)

This paper set out to assert to what extent - and it which sense pedagogical foundations offer a potential for serving as an inclusive and sustainable model for establishing global intercultural educational program. The paper argues for a necessity of constructing educational design models based on ethical values in terms of participation and inclusion. It makes a plea for the use of design models that enculture a fundamental dialogic/participatory approach across types of participants. It promotes non-authoritarian principles and liberating and empowering ethical values at the same time. In addition, the models have to be based in a realistic and strategic context experiencing the needs of the networked society and the knowledge economy. Key issues have been identified, described and discussed that are envisioned to promote sound sustainability and global educational growth. 


\section{References}

Anderson, T. (2016). The theory and Practice of Online Learning ( $2^{\text {nd }}$ ed.). CA: AU Press.

Bates, A. W. (2015). Teaching and learning in a digital age. Guidelines for designing teaching and learning. Creative Commons CC.

Crawley, R. L. (2014). Favor. An autoethnography of survival. In R. M. Boylorn \& M. P. Orbe (Eds.), Critical Autoethnography - Intersecting Cultural Identities in Everyday Life. Walnut Creek, CA: Left Coast Press, Inc.

Edwards, A. (2007). Relational Agency in Professional Practice: A CHAT Analysis. An International Journal of Human Activity Theory, 1, 1-17.

Garrison, R. (1997). Self-Directed Learning: Toward a Comprehensive Model. Adult Education Quarterly, 48(1), 18-33.

Heidegger, M. (1977). The Question Concerning Technology. In D. F. Krell (Ed.), Basic Writings (p. 287). Harper \& Row.

Heidegger, M. (1996). Being and Time. A Translation of "Sein und Zeit". Translated by Joan Stambaugh ( $7^{\text {th }}$ ed.). Albany, New York: SUNY Press.

Helms, N. H., \& Agerbæk, L. (2010). Nettets loeringstopografi. Et anslag til didaktisk kortlogning af metaverse, i Onedge 2_10. Knowledge Lab, University of Southern Denmark.

Knowles, M. (1975). Self-Directed Learning: A Guide for Learners and Teachers. Chicago, IL: Follett Publishing Company.

Kreins, K., \& Kirchner, P. A. (2001). Designing sociable CSCL Environments. In J. W. Strijbos, P. A. Kirchner, \& R. L. Martens (Eds.), What We Know About CSCL and Implementing It in Higher Education. Boston, USA: Klüver Academic Publishers.

Mason, R. D. (Ed.) (1993). Computer Conferencing: The Last Word. Victoria, Canada: Beach Holme Publishers.

Miyake, N. \& Koschmann, T. D. (2002). Realizations of CSCL Conversations: Technology Transfer and the CSILE Project. In T. Koschmann, R. Hall, \& N. Miyake (Eds.), CSCL 2: Carrying forward the conversation. Mahwah, NJ: Lawrence Erlbaum.

Ó Murchú, D., \& Sorensen, E. K. (2004). Online Master Communities of Practice: Collaborative Learning in an Intercultural Perspective. European Journal of Open and Distance Learning, 2004/I. Retrieved from http://www.eurodl.org/?p=archives\&year=2004\&halfyear=1\&abstract=96

Roschelle, J., \& Teasley, S. (1995). The construction of shared knowledge in collaborative problem solving. In C. E. O’Malley (Ed.), Computer Supported Collaborative Learning (pp. 69-97). Heidelberg: Springer-Verlag. 
Sorensen, E. K. (1993). Dialogues in networks. In P. B. Andersen, B. Holmqvist, \& J. F. Jensen (Eds.), The Computer as Medium (pp. 389-421). Cambridge, UK.

Sorensen, E. W. K. (2005). Networked elearning and collaborative knowledge building: design and facilitation. Contemporary Issues in Technology and Teacher Education (CITE), 4(4).

Sorensen, E., \& Brooks, E. I. (2018). Designing Inclusive Reflective Learning with Digital Democratic Dialogue Across Boundaries and Diversities. In E. I. Brooks \& A. Brooks (Eds.), Interactivity, Game Creation, Design, Learning, and Innovation: $6^{\text {th }}$ International Conference, ArtsIT 2017, and Second International Conference, DLI 2017, Heraklion, Crete, Greece, October 30-31, 2017 (pp. 251-261).

Stahl, G. (2006). Group Cognition. Computer Support for Building Collaborative Knowledge. Cambridge, Massachusetts, USA: The MIT Press.

Winograd, T., \& Flores, F. (1986). Understanding Computers and Cognition: A New Foundation for Design. NY, USA: Addison-Wesley Publishing Company.

Zeldin, T. (1994). An Intimate History of Humanity. London: Minerva. 